\title{
Gender Differences on Self-disclosure in Face-to-Face Versus E-mail Communication
}

\author{
Tong Yu \\ China Jiliang University \\ e-mail: mailtoyt@126.com
}

\begin{abstract}
Computer-mediated communication patterns have revolutionized traditional interpersonal communication. This study investigates gender differences of self-disclosure in face-to-face communication and e-mail usage. 297 Chinese students were included in the study. Participants completed a questionnaire regarding the degree of self-disclosure on different conversational topics and to selected target persons, in the forms of face-to-face communication and electronic-mail communication respectively. Results indicate that females are more likely than males to disclose in both situations. Gender differences in conversational topics were also noted in the paper.
\end{abstract}

Keywords-Self-disclosure; face-to-face communication; computer-mediated communication

\section{INTRODUCTION}

Communication is fundamental in developing and maintaining personal relationships. Self-disclosure, a crucial modality of communication in relationship, has caused scholars' attentions for decades. The ability to reveal personal information to others is related to a healthy personality (Jourard, 1959), and the development of close relationship (Altman \& Taylor, 1973). Self-disclosure is important in psychological health and in successful counseling.

Many factors, including communication media, may affect a person's self-disclosure behavior. Two basic communication channels, computer-mediated communication (CMC) and face-to-face communication (FTF), have been studied with self-disclosure. CMC pattern has revolutionized traditional FTF interaction. With the invention of the Internet, e-mails, messengers and chat-rooms become crucial media for people to communicate with each other. Computer-mediated communication differs from face-to-face form in several ways. For example, communicators can observe each other's verbal and nonverbal languages in FTF situation but not in CMC form without the help of visual or auditory computer tools.

It is argued that the richness of communication media results in different extents in self-disclosure. Research tends to support that when individuals communicate in $\mathrm{CMC}$ settings, they pay less attentions to the external environment while focusing more on their private selfs, which leads to the willingness to reveal more about themselves and their real thoughts. Tidwell and Walther (2002) found that students who communicate via CMC with others disclose more and use more intimate questions than students in FTF communications. Other studies also support that people disclose more about the self during CMC interactions (e.g., McKenna \& Bargh, 1998; Rosson, 1999).

However, the majority of the previous researches examined $\mathrm{CMC}$ as a general concept, while unique characteristics of different forms of CMC were ignored. With the increasing modalities of CMC appear these days, it is necessary to investigate human communication behaviors in different online communication forms respectively. For instance, email is a relatively traditional CMC format, and its asynchronous feature makes it possible for users to think and then write. But instant messaging (IM) is a real-time messaging format and users may not have that much time for thinking during communication. Taken the complex of CMC form into consideration, the researcher only chose email communication as a CMC format in the current study. It attempts to study self-disclosure in two modes of communication, i.e., face-to-face contact and e-mail communication.

\section{LITERATURE REVIEW}

Self-disclosure is defined as "the process of making the self known to other persons" (Jourard \& Lasakow, 1958, p.91). This process is regarded as the communication through self-disclosing messages to target persons, who may include parents, friends, acquaintances, strangers and so on. Archer (1980) defined self-disclosure as the "act of revealing personal information to others" (p. 183).

Many factors, such as communicative modes, relationship with the target person, may influence an individual's decision on the breadth and depth of disclosure behavior. Gender factor may make the issue even more complicated. In fact, gender differences in self-disclosure behaviors have been examined, yet inconclusive in many studies. Many studies supported the notion that females disclose more than males do (e.g., Shaef, 1981; Willlliams, 1985), whereas some investigations reported no significant sex differences in self-disclosure (e.g., Cho, 2007; Sprecher \& Hendrick, 2004). A few studies even found that men disclose more than women (e.g., Marlatt, 1970; Mickelson \& Stevic, 1971).

Dindia and Allen (1992) then conducted a meta-analysis of 205 studies, involving 23,702 subjects, and concluded that the inconsistency of gender differences in disclosure in previous results may be due to moderator variables, such as sex of target, relationship to target, etc. For instance, female-female bonds were believed to have the highest 
disclosure rates than male-male or cross-sex bonds (Dolgin, Meyer, \& Schwartz, 1991; Fischer \& Narus, 1981).

Among all the moderators, disclosure topic is no doubt an important one for people's disclosure tendencies. Dolgin and Minowa (1997) replicated the result that women disclose more than men. They found that both men and women, especially men, choose to disclose topics judged with lesser intimacy. Furthermore, they noticed that men tend to disclose more flattering information while women most commonly disclose unflattering information about themselves.

Content influence can be seen in some other studies. Rubin et al. (1980) studied dating couples and indicated that men are more likely to reveal their strengths and women are more likely than men to express their fears. Derlega et al. (1981) also reported that women disclose more than men on feminine topics, which emphasize personal concerns and vulnerabilities. It was suggested that females tend to engage in more emotional disclosures whereas males prefer factual disclosures (Last \& Aharoni-Etzioni, 1995; Papini et al., 1990).

Except for the FTF settings, gender differences were also noted with CMC mode. Special \& Li-Barber (2012) examined self-disclosure and student satisfaction with Facebook and noted males and females differ in the overall level of self-disclosure and the type of information presented on their Facebook profiles. For instance, males disclose more basic information (e.g., one's birthday, hometown) and more contact information (e.g., emails, mobile phone) than females.

It was also found that men actually disclose themselves better in online settings because reduced audiovisual cues can reduce their uneasiness (Wang, Jackson, \& Zhang, 2011). Griffiths et al. (2011) reported that significantly more male gamers than female gamers in multiplayer online role-playing games said that they found it easier to communicate online than offline. While male players make more friends online, female players are more likely to meet their online friends in person, to discuss sensitive issues and to physically date other players (Cole \& Griffiths, 2007).

Barak \& Gluck-Ofri (2007) tried to examine the degree and reciprocity of self-disclosure in online forums. Their results didn't see gender differences in level of self-disclosure, but found that females tend to be more reciprocal than males.

In addition, Valkenburg et al. (2011) reported significant gender differences in the developmental trajectories of self-disclosure with a survey of 690 pre-adolescents and adolescents. The study showed that boys' and girls' disclosure, both online and offline, increased sharply during pre- and early adolescence, and then stabilized in middle and late adolescence. The difference was the increase of girls' disclosure started 2 years earlier than that of boys. The study also suggested that both boys and girls seem to use online self-disclosure to rehearse offline self-disclosure skills.

With so many studies on gender differences in self-disclosure, few of them examined the topic with both FTF and online conditions. Therefore, it would be interesting to see whether there's gender difference on self-disclosure via FTF and email communications. The purpose of this study is then to examine if there are any gender differences on self-disclosure in FTF and email communications, taking both disclosure targets and topics into consideration.

\section{METHOD}

\section{A. Participants}

Altogether 297, including 102 male and 195 female, respondents were recruited in this study. They were undergraduate students at an eastern university in China. The average age was 20.84 years, ranging from 18 to 25 years. The participants were chosen from various academic disciplines. The reported average hours using e-mail per week ranged from 1 hour to 24 hours. 45 students didn't report their average hours using e-mail per week.

\section{B. Instrument}

A revised version of Barnlund's Self-Disclosure Scale (1975) was used in this study. The questionnaire was to test respondents' willingness of disclosure on different conversational topics and to different target persons. 25 items were included in the six categories of conversational topics - 5 items on opinion, 5 items on interests, 3 items for work or study, 4 items for money, 5 items for personality, and 3 items for body. Participants were asked to score their willingness to reveal the information to five types of target persons: father, mother, stranger, acquaintance, and intimate friend, using five-point scales with $1=$ "not at all"to 5="very much". The Cronbach Alpha for the overall scale was .987. Thus the scale is considered highly reliable in this study.

\section{RESUlts}

An independent t-test was used to test the gender differences when disclosing to different targets. The overall findings of this study suggested that female participants were more willing to disclose both in FTF interactions and through emails than males. There were no obvious gender differences on disclosure via email to father, mother and strangers. It is also interesting to see that in this study males disclosed more to intimate friends in FTF settings than females did. Furthermore, the results showed that participants, both males and females, prefer to disclose more in FTF settings than through emails to father, mother, and strangers. However, they were willing to disclose more via emails rather than face to face to acquaintances and intimate friends. (see Table 1)

Except the differences to different targets, possible gender differences on different conversational topics were also tested.

An independent t-test was used to test the gender differences on different topics. The results show that female participants tended to reveal more on topics concerning opinion, work, personality and body through face to face settings than males. The results also showed that no significant gender differences were found in participants' disclosure via email except when the topic is related to money. Males disclosed more on money through email than females. (see Table 2)

\section{Discussions}

This study investigated gender differences on self-disclosure behaviors in FTF settings and email 
interactions. Overall, the results supported that females disclose more than males both in face-to-face and via email communications. Generally speaking, females in this study tended to reveal more to different targets, regardless whom, than males. One of the reasons for this phenomenon can be attributed to the stereotype of sex roles in our society. According to Jourard (1971), men disclose less than women because the male role prohibits men's self-disclosure. The society generally expects men to be tough, strong, aloof, and emotionally unexpressive, while women to be nurturing and expressive. The sex role has been taught and developed to a person since $\mathrm{s} / \mathrm{he}$ was born and cannot be easily changed, even with the mask of the screen. Because of the sex role, women are accepted to express emotions publicly and frequently, but men are discouraged to do so.

The reason that no significant gender differences were found in e-mailing father, mother and strangers was many participants indicated that their parents do not have an email box and they were not used to communicate with parents through emails.

As mentioned before, conversational content would be a factor to affect disclosure extent. In this study, topic tends to be a variable in FTF communication but not in email situation. It seems that women are more likely than men to reveal face-to-face on opinion, work, personality and body. This finding supports the notion that women disclose more than men about personal and emotional information. But for topics such as interest and money, no clear gender differences were found. It is possible that interest would be a safe or neutral topic for both men and women to discuss.

Money was the only topic that men were likely to reveal more than women through emails in the current study, yet the overall desire for this topic via email, for both men and women, was the lowest among all topics.

Previous research suggests that people disclose more about themselves during computer-mediated communication than they do in fact-to-face communication, which was not a case in our study. The possible reason is that E-mail is no longer a very popular tool for online communication these days with the development of computer technology. Many young people even think e-mail to be a technology for "old people". Instead, instant messaging is more popular than emails. The lack of instant reciprocity may be a big barrier for it as a computer-mediated communicative channel.

It is also interesting to see that in this study men disclosed more than women to intimate friends in FTF settings, which is not consistent to some other studies.

The study is not without limitations. The instrument applied in this study only tested participants' self-disclosure behaviors to different targets on different topics with self-report method. Self-disclosure is a very complicated behavior concerning many factors, such as personality, relationship with target persons, social class, etc. For example, Jourard and Lasakow (1958) found that an individual's disclosure to father or mother correlated significantly with liking. Some scholars also believe that disclosure is closely related to a person's personality traits, including mental health, which could not be indicated in the scale used in this study. Self-report method may also affect the result to some extent. Further studies may use both quantitative and qualitative data to compare the results with this study. What's more, with the development of computer technology, there are more and more computer-mediated communicative modes appear, such as SNSs, which deserve more concerns. Whether the ethnic background of subjects influences the results can also be considered in the future.

\section{REFERENCES}

[1] Altman, I., \& Taylor, D. (1973). Social penetration: The development of interpersonal relationships. New York: Holt, Rinehart, \& Winston.

[2] Archer J. L. (1980). Self-disclosure. In The Self in Social Psychology, Wegner D. Vallacher R (eds). Oxford University Press: London; 183-204.

[3] Barak, A., \& Gluck-ofri, O. (2007). Degree and reciprocity of self-disclosure in online forums. CyberPsychology \& Behavior, 10(3), 407-417.

[4] Bond, B. J. (2009). He posted, she posted: Gender differences in self-disclosure on social network sites. Rocky Mountain Communication Review, 6(2), 29-37.

[5] Cho, S. H. (2007). Effects of motivations and gender on adolescents' self-disclosure in online chatting. CyberPsychology \& Behavior, 10(3), 339-345.

[6] Cole, H., \& Griffiths, M. D. (2007). Social interactions in massively multiplayer online role-playing gamers. CyberPsychology \& Behavior, 10(4), 575-584

[7] Derlega, V. J. Durham, B., Gockel, B., \& Sholis, D. (1981). Sex differences in self-disclosure: Effects of topic content, friendship and partner's sex. Sex Roles, 7(4), 433-447.

[8] Dindia, K. \& Allen, M. (1992). Sex differences in self-disclosure: A meta-analysis. Psychological Bulletin, 112(1), 106-124.

[9] Dolgin, K. G., Meyer, L, \& Schwartz, J. (1991). Effects of gender, target's gender, topic, and self-esteem on disclosure to best and middling friends. Sex Roles, 25(5/6), 311-329.

[10] Dolgin, K. G., \& Minowa, N. (1997). Gender differences in self-presentation: A comparison of the roles of flatteringness and intimacy in self-disclosure to friends. Sex Roles, 36(5/6), 371-380.

[11] Fischer, C., \& Narus, L. (1981). Sex roles and intimacy in same-sex and other sex relationships. Psychology of Women Quarterly, 5, 444-455.

[12] Griffiths, M., Hussain, Z., Grusser, S. M., Thalemann, R., Cole, H., Davies, M. N. O., \& Chappell, D. (2011). Social interactions in online gaming. International Journal of Game-Based Learning, 1(4), 20-36.

[13] Grinter, R. E., \& Palen, L. (2002). Instant Messaging in teen life. Retrieved June 9, 2010, from http://portal.acm.org/citation.cfm? $\mathrm{id}=587082$

[14] Jourard, S. M., \& Lasakow, P. (1958). Some factors in self-disclosure. Journal of Abnormal and Social Psychology, 56, 91-98.

[15] Jourard, S. M. (1959). Healthy personality and self-disclosure. Mental Hygiene, 43, 499-507.

[16] Last, U., \& Aharoni-Etzioni, A. (1995). Secrets and reasons for secrecy among school-aged children: Developmental trends and gender differences. Journal of Genetic Psychology, 156, 191-203.

[17] Marlatt, G. A. (1970). A comparison of vicarious and direct reinforcement control of verbal behavior in an interview situateion. Journal of Personality and Social Psychology, 10, 284-200.

[18] Mckenna, K. Y. A, \& Bargh, J. A. (1998). Coming out in the age of the Internet: Identity 'demarginalization' through virtual group participation. Journal of Personality and Social Psychology, 75, 681-694..

[19] Mickelson, D. J., \& Stevic, R. R. (1971). Differential effects of facilitative and nonfacilitative behavioral consequences. Journal of Counseling Psychology, 18, 314-319. 
[20] Papini, D. R., Farmer, F. F., Clark, S. M., Micka, J. C., \& Barnett, J. K. (1990). Early adolescent age and gender differences inpatterns of emotional self-disclosure to parents and friends. Adolescence, 25, 959-976.

[21] Schouten, A. P., Valkenburg, P. M., \& Peter, J. (2009). An Experimental Test of Processes Underlying Self-Disclosure in Computer-Mediated Communication. Journal of psychosocial Research on Cyberspace, 3(2): article 1.

[22] Special, W. P., \& Li-Barber, K. T. (2012). Self-disclosure and student satisfaction with Facebook. Computers in Human Behavior, 28, 624-630.
[23] Sprecher, S., \& Hendrick, S. S. (2004). Self-disclsoure in intimate relationships: Associations with individual and relationship characteristics over time. Journal of Social \& Clinical Psychology, 23 , 857-877

[24] Valkenburg, PM., Sumter, SR., Peter, J. (2011). Gender differences in online and offline self-disclosure in pre-adolescence and adolescence. British Journal of Developmental Psychology, 29(2), 253-269.

[25] Wang, J. L., Jackson, L. A., \& Zhang, D. J. (2011). The mediator role of self-disclosure and moderator roles of gender and social anxiety in the relationship between Chinese adolescents' online communication and their real-world social relationships. Computers in Human Behavior, 27(6), 2161-2168.

TABLE I. GENDER DIFFERENCES IN DISCLOSING TO DIFFERENT TARGETS

\begin{tabular}{|c|c|c|c|c|c|c|}
\hline & \multicolumn{2}{|c|}{ Male } & \multicolumn{2}{|c|}{ Female } & \multirow[t]{2}{*}{ F-value } & \multirow[t]{2}{*}{ Sig } \\
\hline & $\mathrm{M}$ & SD & $\mathrm{M}$ & SD & & \\
\hline FTF All & 3.04 & .78 & 3.45 & .56 & 11.83 & $.001 *$ \\
\hline EM All & 2.96 & .72 & 3.22 & .55 & 8.07 & $.005 *$ \\
\hline Father All & 2.88 & .78 & 3.10 & .60 & 5.36 & $.021 *$ \\
\hline Mother All & 3.08 & .76 & 3.39 & .57 & 9.73 & $.002 *$ \\
\hline Stranger All & 3.08 & .71 & 3.48 & .54 & 5.51 & $.020 *$ \\
\hline Acquaint All & 3.27 & .87 & 3.78 & .58 & 16.87 & $.000 *$ \\
\hline Intimate All & 2.70 & .65 & 2.91 & .53 & 8.22 & $.004 *$ \\
\hline Father FTF & 3.35 & .92 & 3.82 & .63 & 12.47 & $.000 *$ \\
\hline Father EM & 2.4 & .99 & 2.38 & .90 & .585 & .445 \\
\hline Mother FTF & 3.26 & 1.13 & 3.72 & .83 & 9.99 & $.002 *$ \\
\hline Mother EM & 2.89 & .72 & 3.06 & .60 & 3.63 & .058 \\
\hline Stranger FTF & 3.27 & .89 & 3.86 & .61 & 12.91 & $.000 *$ \\
\hline Stranger EM & 2.89 & .83 & 3.09 & .69 & 2.64 & .106 \\
\hline Acquaint FTF & 3.18 & 1.09 & 3.75 & .81 & 7.58 & $.006 *$ \\
\hline Acquaint EM & 3.37 & .90 & 3.81 & .61 & 13.98 & $.000 *$ \\
\hline Intimate FTF & 2.13 & .79 & 2.09 & .65 & 4.48 & $.035 *$ \\
\hline Intimate EM & 3.27 & .96 & 3.74 & .69 & 13.62 & $.000 *$ \\
\hline
\end{tabular}

*significant at $\mathrm{p}<.05$

TABLE II. GENDER DIFFERENCES IN DISCLOSING ON DIFFERENT CONVERSATIONAL TOPICS

\begin{tabular}{|c|c|c|c|c|c|c|}
\hline & \multicolumn{2}{|c|}{ Male } & \multicolumn{2}{|c|}{ Female } & \multirow[t]{2}{*}{ F-value } & \multirow[t]{2}{*}{$\mathrm{p}$} \\
\hline & $\mathrm{M}$ & $\mathrm{SD}$ & $\mathrm{M}$ & SD & & \\
\hline Opinion FTF & 3.48 & 1.07 & 4.05 & .72 & 17.128 & $.000 *$ \\
\hline Opinion EM & 2.64 & 1.20 & 2.76 & 1.23 & .048 & .826 \\
\hline Interest FTF & 3.44 & 1.07 & 3.87 & 1.02 & 3.041 & .082 \\
\hline Interest EM & 2.85 & 1.25 & 3.15 & 1.30 & .496 & .482 \\
\hline Work FTF & 3.27 & 1.20 & 3.89 & .84 & 18.045 & $.000 *$ \\
\hline Work EM & 2.21 & 1.12 & 2.29 & 1.16 & .007 & .932 \\
\hline Money FTF & 3.39 & 1.11 & 3.75 & .92 & 2.902 & .090 \\
\hline Money EM & 1.85 & 1.07 & 1.37 & .67 & 43.473 & $.000 *$ \\
\hline Personality FTF & 3.38 & 1.14 & 3.95 & .77 & 16.780 & $.000 *$ \\
\hline Personality EM & 2.43 & 1.24 & 2.32 & 1.13 & .784 & .377 \\
\hline Body FTF & 2.98 & 1.11 & 3.20 & .78 & 12.098 & $.001 *$ \\
\hline Body EM & 2.15 & 1.18 & 1.95 & 1.01 & 3.261 & .072 \\
\hline
\end{tabular}

* significant at $\mathrm{p}<.05$ 